\title{
CONTRIBUIÇÃO PARA UM POSSÍVEL HISTÓRICO DO ENSINO COLETIVO DE INSTRUMENTOS MUSICAIS
}

\author{
Contribution to a possible history of the \\ collective teaching of musical instruments
}

\author{
Contribución a una posible historia de \\ la enseñanza colectiva de instrumentos \\ musicales
}

\author{
WiLson RogéRIO dOS SANTOS \\ Universidade Federal do Tocantins \\ rg_santos@uft.edu.br
}

\author{
Ana Roseli Paes dos Santos \\ Universidade Federal do Tocantins \\ anaroseli@uft.edu.br
}

\begin{abstract}
Resumo: O objetivo deste trabalho é discutir alguns conceitos referentes ao surgimento do sistema de ensino coletivo de instrumentos musicais e procurar trazer à luz novas informações que possam contribuir para a compreensão do processo histórico de implantação desse sistema, especialmente nos EUA e Europa, além de debater informações referentes à sua implantação em nosso país. A partir de autores de referência, como Charles Sollinger, Kevin Thompson e James Keene, o recorte apresenta dados que objetivam a tentativa de estabelecer um histórico sobre o tema. A proposta é reavaliar alguns conceitos e principalmente datas utilizadas até o momento, além de auxiliar, propor e incentivar novas iniciativas de investigação sobre o assunto.
\end{abstract}

Palavras-chave: Ensino coletivo de instrumentos musicais. Ensino de música. Educação musical.

\begin{abstract}
The objective of this work is to discuss some concepts related to the emergence of the collective education system of musical instrument and seek to bring to light new information that may contribute to the understanding of the historical process of implementation of this system, especially in the USA and Europe, in addition to discussing information regarding its implementation in our country. From reference authors like Charles Sollinger, Kevin Thompson and James Keene the clipping presents data that aim at trying to establish a history on the topic. The proposal is to reassess some concepts and mainly dates used so far, besides helping, proposing and encouraging new research initiatives on the subject.
\end{abstract}

Keywords: Collective teaching of musical instruments. Music teaching. Music education.

Resumen: El objetivo de este trabajo es discutir algunos conceptos relacionados con el surgimiento del sistema educativo colectivo de instrumentos musicales y tratar de sacar a la luz nueva información que pueda contribuir a la comprensión del proceso histórico de implantación de este sistema, especialmente en los EUA y Europa, además de discutir información sobre su implementación en nuestro país. A partir de autores de referencia como Charles Sollinger, Kevin Thompson y James Keene, el recorte presenta datos que intentan establecer una historia sobre el tema. La propuesta es reevaluar algunos conceptos y especialmente las fechas utilizadas hasta ahora, además de ayudar, proponer y alentar nuevas iniciativas de investigación sobre el tema.

Palabras clave: Enseñanza colectiva de instrumentos musicales. Enseñanza de la música. Educación musical. 


\section{INTRODUÇÃO}

Devido à importância do ensino coletivo de instrumentos como prática musical que vem se estabelecendo como uma das mais significativas nos últimos tempos, diversos autores brasileiros escreveram sobre as possiveis origens dessa maneira de ensinar. A totalidade deles usou o assunto como forma de contextualizar seu trabalho sem tentativa de esgotar o tema, pois, propriamente, não houve a necessidade de encontrar um possivel "elo perdido" na criação do ensino coletivo, e, sim, de oferecer uma perspectiva da metodologia dentro de um contexto histórico.

O objetivo deste trabalho é rever alguns conceitos referentes ao assunto e procurar trazer à luz informações que possam contribuir para a compreensão do processo histórico de implantação do ensino coletivo, especialmente nos EUA e Europa, e debater informações referentes à sua implantação em nosso país; o interesse pelo tema surgiu quando foram estabelecidos os fundamentos para a tese de doutoramento de um dos autores deste artigo (Santos, 2016), sendo que, naquele momento, foi possível perceber algumas discrepâncias relacionadas a datas e fatos narrados e utilizados como referencial histórico para o assunto. ${ }^{1}$

Embora a tese tenha utilizado procedimentos metodológicos como a notação com guia de análise, a estatística descritiva e o processo de emparelhamento, para o recorte em questão o método adotado foi o bibliográfico/ documental.

É importante destacar que o texto procura trazer um histórico da implantação do ensino coletivo, por isso trata principalmente dos instrumentos orquestrais e do teclado (piano em grupo), pois foram os primeiros a serem ensinados com a utilização dessa técnica; o fato de deixarmos de lado instrumentos representativos para a área, como o violão, está relacionado a esse motivo.

Da mesma maneira é importante registrar que se trata de um recorte objetivando definir o processo histórico de implantação do sistema ${ }^{2}$ e não de uma revisão bibliográfica sobre o assunto; tal revisão também foi realizada no momento da construção da tese, mas por questões de espaço editorial, deverá ser divulgada no artigo "Situação e perspectivas da pesquisa sobre ensino coletivo de instrumentos no Brasil".

\footnotetext{
1 Um desenvolvimento da discussão sobre as possíveis origens do ensino coletivo na Europa e especialmente nos EUA pode ser feito a partir de livros e teses como os de Michael L. Mark e Charles L. Gary (2007); Sally Monsour (1959); Charles E. Sollinger (1970).

2 Sistema enquanto: "Reunião coordenada e lógica de princípios ou ideias relacionadas de modo que abranjam um campo do conhecimento [...] Técnica ou método empregado para um fim precípuo [...] Modo, maneira, forma, jeito" (Ferreira, 1999, p. 1865).
} 


\section{ENSINO COLETIVO DE INSTRUMENTOS MUSICAIS}

A partir dos trabalhos de Montandon (1992), Oliveira (1998), Ying (2007) e Santos (2001), podemos observar que, no Brasil, existe uma linha de raciocínio bem definida na tentativa estabelecer um histórico do ensino coletivo. Oliveira (1998, p. 7) nos oferece um bom ponto de partida quando cita em sua dissertação de mestrado o The musical academy, de Lewis A. Benjamin, método que utiliza o ensino coletivo e que teve seu sétimo volume ${ }^{3}$ editado em 1851; também menciona o Maidstone, movimento inglês de ensino de música, afirmando que em 1908 "400.000 alunos de 5.000 escolas britânicas estavam, efetivamente, tocando e estudando violino". Sem dúvida essa é a referência mais utilizada pelas pesquisas realizadas no Brasil a partir de então (Cruvinel, 2005, p. 69; Rodrigues, 2012, p. 21-22; Ying, 2007, p. 13).

Sabemos que em Nova York a família Benjamin ensinou música, especialmente violino. Lewis A. Benjamin ensinou violino em grupo por volta da metade do século XIX, e segundo Sollinger (1974) foi um dos primeiros professores a ensinar um instrumento orquestral dessa maneira. Ele trabalhou em Nova York durante os anos de 1847 a 1891 e criou uma espécie de consórcio musical: a The Musical Academy, onde as classes eram organizadas em forma de sociedade e cada membro pagava cotas semanais para custear as aulas.

Da mesma maneira que acontece hoje, nesse processo, as atividades sociais eram parte importante e contribuiam para o sucesso do empreendimento. Os alunos também participavam de apresentações públicas e essa participação era parte integrante no acordo das aulas, sendo que os alunos mais avançados eram isentos de taxas, desde que concordassem em participar do curso por no mínimo dois anos. Foi para esta academia que Lewis Benjamin escreveu o método citado (The musical academy).

Posteriormente a família Benjamin (filhos e irmãos) expandiu seus negócios e abriu outras escolas, além de iniciar a venda de instrumentos e edições musicais, atividades que representaram boa parte de seus rendimentos. Para divulgar seus negócios foram criados festivais anuais que reuniam mais de 3000 alunos; esses festivais aconteceram com grande sucesso entre 1883 e 1891 e representam bons exemplos das apresentações reunindo grande número de participantes que se tornaram populares na época. Entusiasmado com o ensino coletivo, Benjamin acreditava que o sistema fornecia um maior estimulo para os alunos e inclusive incentivou os pais a participarem de discussões sobre os problemas pedagógicos encontrados no trabalho, utilizou sistemas de graduação de desenvolvimento onde os alunos trocavam de turmas a partir da proficiência do instrumento e surpreendentemente seus festivais influenciaram a reintrodução do ensino de música vocal nas escolas (Keene, 2009, p. 290 et seq.).

Já o Maidstone surge na segunda metade do século XIX, quando T. Mee Pattison, assessor musical da JG Murdoch \& Co., editora de música e

\footnotetext{
3 É o sétimo volume o único que restou (e pode ser documentado) da coleção editada por Benjamin.
} 
fabricante de instrumentos baseada em Londres, propõe para a empresa a criação de um projeto com o objetivo de promover aulas de violino para crianças em idade escolar. O projeto previa o fornecimento, a preços módicos, de violinos, materiais pedagógicos e professores. Além disso os alunos foram autorizados a pagar os custos dos instrumentos em parcelas, geralmente um xelim por semana. Esse método foi batizado de Escola Nacional de Todos os Santos, em Maidstone, Inglaterra, e ficou conhecido como movimento Maidstone.

Em 1897, a empresa formou a Murdoch Maidstone School Orchestra Association (MSOA) para promover esse método. No auge da popularidade o movimento contava com 400 mil alunos, sendo que um em cada dez alunos da população escolar participava das aulas do projeto. Segundo Robin Deverich (2013, tradução nossa), em seu artigo sobre o assunto, o professor H. Farnsworth, um proeminente educador musical americano, expressou seu espanto com os resultados alcançados pelas aulas de violino do movimento:

[...] assisti a um concerto dado pelas orquestras escolares, onde 1.450 jovens instrumentistas participaram. É surpreendente ver o que pode ser feito nessas condições [...] Estima-se que apenas em Londres há mais de 300 dessas classes de violino com uma adesão média de 25 alunos e praticamente não há uma cidade na Inglaterra onde não exista uma ou mais dessas classes.

Embora seja um ponto de partida bastante aceitável e lógico, os anos de 1851 (The musical academy) e 1908 (Maidstone) podem ser questionados como datas de início de um processo de implantação do ensino coletivo nos EUA ou na Europa, pois é fato que existiram atividades anteriores que merecem ser consideradas. Para comprovar tal observação basta analisar o próprio livro utilizado por Oliveira, A history of music education in the United States, que nos permite perceber que Keene, embora discorra sobre o trabalho da família Benjamin ao longo de cinco páginas (Keene, 2009, p. 290295), demonstrando a importância da participação dessa família na história do ensino de música nos EUA durante o período compreendido entre 1847 e 1891, cita, sustentado pela tese de doutorado de Charles Sollinger (1970), os irmãos James e Joseph Howell, ${ }^{4}$ que se dedicaram a aulas de música e venda de instrumentos entre 1849 e 1861 , e D. L. Elder, ${ }^{5}$ que trabalhou como professor de música no Tennessee em 1839 (Keene, 2009, p. 289).

\footnotetext{
4 Os irmãos Howell estabeleceram-se na cidade de Cotton Plant (Arkansas) por volta de 1838. Cotton Plant era próxima a Little Rock, cidade que possuía, na época, entre sete e dez escolas, sendo que essas instituições ensinavam tanto música instrumental quanto música vocal. James L. Howell e seu irmão Joseph ensinaram música e venderam instrumentos de 1838 até 1861, ano da eclosão da guerra civil americana. Joseph Howell escreveu seu método, New class book, por volta de 1859 (Keene, 2009, p. 289).

5 D. L. Elder ensinou teoria musical e música instrumental tanto em classes particulares como em classes coletivas na cidade de Knoxville, Tennessee, por volta de 1839.
} 
O próprio Sollinger (1974, p. 9, tradução nossa) chama atenção para este equivoco:

Acredita-se geralmente que o ensino instrumental na América começou como influência do movimento Maidstone, na Inglaterra. Pelo contrário, o primeiro registro de aulas de ensino instrumental nos Estados Unidos ocorreu em Boston, em 1800, quase um século antes do movimento Maidstone. Em seu conservatório, Gottlieb Graupner, Francisco Mallet e Filippo Trajetta utilizaram o ensino de música em grupo. Em 1839, na Academia Feminina de Knoxville, Tennessee, o sr. D. L. Elder ensinou vários instrumentos em grupo. Pouco se sabe sobre esses primeiros empreendimentos, mas durante a primeira metade do século XIX instrumentos foram ensinados coletivamente com sucesso em várias partes do país.

Essas atividades iniciais não estavam relacionadas entre si nem foram numerosas, elas foram desenvolvidas espontaneamente por professores individuais que possuiam a base necessária, quando influenciados por fatores mencionados acima. Certamente, nem todos os professores publicaram métodos, anunciaram em jornais ou tiveram artigos escritos sobre eles, mas com aqueles que tiveram suas atividades de ensino registradas na imprensa verificou-se a utilização das aulas de ensino de cordas em grupo. ${ }^{6}$

Em seu trabalho, Sollinger (1974, p. 70) ainda relaciona a publicação, em 1851, de um método de ensino coletivo de instrumentos heterogêneos, ${ }^{7}$ que se apresentava com duas partes agudas e uma grave e era destinado a atender pequenas orquestras formadas por "violins, bass viol, flute, clarionette, bugle and trombone". ${ }^{8}$

A literatura sobre o assunto apresenta também fortes referências ao trabalho desenvolvido por Johann Bernhard Logier, professor de piano na cidade de Dublin por volta de 1815, e como professores norte-americanos e europeus foram visitar suas aulas para reproduzir sua metodologia (Daniel, 2005, p. 27). Montandon (1992, p. 8) diz que, em 1815, Logier, alemão de nascimento e residente em Londres desde 1805, passou a desenvolver um

\footnotetext{
6 "It is commonly believed that instrumental class teaching in America began as an influence from the Maidstone movement in England. On the contrary, the first recorded instance of instrumental class teaching in the United States occurred in Boston in 1800, almost a century before the Maidstone movement. In their conservatory. Gottlieb Graupner, Francis Mallet, and Filippo Trajetta utilized class instruction in applied music. In 1839, in the Female Academy of Knoxville, Tennessee, Mr. D. L. Elder taught various instruments in classes. Little is known of these early ventures, but during the first half of the 1800's, instruments were successfully taught in classes in a number of isolated parts of the country. These early activities were not related or numerous; they were developed spontaneously by individual teachers possessing the necessary background, when influenced by factors mentioned above. Certainly, not all teachers published methods or advertisements in newspapers or had articles written about them, but those that have had their teaching activities recorded in print verify the existence of string class teaching."

7 Cf. Balles (1851).

8 Grosso modo seriam: violinos, violoncelos, flautas, clarinetes, trompetes e trombones.
} 
sistema de aulas de piano em grupo em sua academia em Dublin, ao qual denominou de "Novo Sistema de Educação Musical", de acordo com o nome de um de seus livros instrucionais. Entretanto, é bom deixar registrado que Thompson (1983, p. 22-23, tradução nossa), sendo uma das maiores referências no assunto, critica violentamente esse sistema de ensino:

A advertência anterior poderia muito bem ter sido estendida para se proteger contra os professores fraudulentos, em particular, de Johann Bernard Logier, que dava aulas de piano em Dublin em 1815. Não é de surpreender que, com as fortes ligações entre americanos e irlandeses, muitos professores americanos se matricularam em suas aulas. Logier, um alemão de nascimento, tinha viajado para a Irlanda como um músico de banda militar, lá ele rapidamente criou aulas de piano. Um impostor, o chamado "sistema" parece ter sido mais aritmético do que educativo ou musical. Ele levou a ideia de quantidade da Revolução Industrial para niveis absurdos e criou a fama de

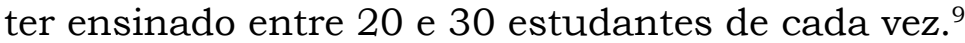

Julgamentos à parte, tal contestação não nos impede que consideremos o ano de 1815 como outro possivel ponto de partida para a implantação de algum tipo de sistema de ensino coletivo, por meio de Logier e seus seguidores, trazendo o surgimento do ensino coletivo para datas mais próximas ao início do século XIX. O próprio Logier é mencionado e recebe um tratamento bem mais positivo em vários outros trabalhos, como o de Fisher (2010, p. 3, tradução nossa):

A aplicação do ensino de piano em grupo apareceu pela primeira vez em Dublin, na Irlanda, por volta de 1815, quando o músico alemão Johann Bernhard Logier começou com a instrução dos conceitos teórico-musicais e sua posterior aplicação no teclado. Assim, as aulas de piano e teclado em grupo nasceram. Professores de piano da América, bem como de muitos países europeus, frequentaram as aulas de Logier e voltaram para casa a fim de introduzir o ensino de grupo em seus respectivos países. ${ }^{10}$

\footnotetext{
9 "An earlier caveat might well have been extended to guard against fraudulent teachers, in particular one Johann Bernard Logier who taught piano classes in Dublin in 1815. It is hardly surprising that with the strong Irish American connections which have existed, teachers from the United States enrolled in his classes. Logier, a German by birth, had travelled to Ireland as a military bandsman whore he rapidly established classes for piano teacher. A charlatan, his so-called 'system' seems to have been more arithmetical than educative or musical. He took the quantity notion of the Industrial Revolution to absurd lengths and is reputed to have taught between twenty and thirty students at a time."

10 "The application of group piano teaching first appeared in Dublin, Ireland, around 1815 when the German musician Johann Bernhard Logier began instruction of musical theoretical concepts and their subsequent application at the keyboard. Thus, group piano and keyboard harmony classes were born. Piano teachers from America as well from many European countries attended Logier's classes and returned home to introduce group teaching to their respective countries."
} 
Tal ideia é corroborada por Daniel, sustentado por vários pesquisadores (Dillon, 1999; Loesser, 1954; Zhukov, 1999), que, embora apresente, na maior parte, referências que nos remetem aos métodos de instrução ao teclado, afirma que o ensino em grupo já existe desde o início dos anos 1800 e que seu desenvolvimento se deveu ao beneficio econômico que gerava para os professores e ao crescente aumento do poder aquisitivo da população de classe média que passou a desejar ter acesso ao ensino musical.

Outro ponto sensivel na discussão das origens do ensino coletivo é a questão do sistema conservatorial, da implantação dos conservatórios na Europa e especialmente da utilização de master classes como recurso pedagógico. Ao contrário da opinião de autores que consideram o sistema de master class como um dos modelos de ensino coletivo, presume-se que seja mais legítimo considerá-lo como sendo um recurso para o ensino coletivo, desde que utilizado em conjunto com aulas coletivas.

É natural que exista uma confusão em torno dos termos e que o momento histórico do surgimento de um e outro sistema tenham sido sobrepostos, além de todos eles serem pensados para viabilizar o atendimento de muitas pessoas ao mesmo tempo, mas, da mesma forma que a prática de orquestra e as aulas individuais podem colaborar com o ensino coletivo, mas não são ensino coletivo, o master class pode colaborar, mas não é ensino coletivo per se.

Diversos autores partilham essa opinião, e entre eles podemos citar Montandon (2004, p. 47):

[...] no meu entender, a aula de instrumento que coloca vários alunos juntos (muitas vezes para economizar tempo), com um tocando determinado repertório padrão enquanto os outros escutam não é "ensino em grupo" ou "aprendizagem em grupo" mas aulas individuais dadas em grupo.

e Daniel (2005, p. 21, tradução nossa), que discute e distingue cada modelo:

Como é evidente a partir da literatura (por exemplo, Jørgensen, 2000, Ehrlich, 1990, Loesser, 1954), ${ }^{11}$ os modelos de aulas individuais, master classes e o ensino em grupo foram introduzidos durante os séculos XVIII e XIX, embora as origens exatas e fundamentos de cada um permaneçam dificeis de rastrear. ${ }^{12}$

Continuando seu raciocinio, Daniel relata que o modelo de master class obteve destaque na cultura de ensino do piano no século XIX, quando esse modelo apresentava, no centro, o mestre ou o guru e, tinha como modus operandi a necessidade de os alunos absorverem a sabedoria do detentor do conhecimento. O termo certamente se desenvolveu durante o tempo dos

${ }^{11}$ Cf. Jørgensen (2000), Ehrlich (1990) e Loesser (1954).

12 "As is clear from the literature (e.g. Jørgensen 2000, Ehrlich 1990, Loesser 1954), the one to one lesson, master class and group teaching models were introduced during the 18th and 19th centuries, although the exact origins and rationale for each remain difficult to trace." 
pianistas românticos, com o mestre no centro da classe. Na verdade, muitas das descrições de Liszt ${ }^{13}$ por seus alunos se referem a ele apenas como $O$ Mestre. O modelo variou de pequenos grupos de alunos tocando e ouvindo a classes de mais de uma centena de alunos (Daniel, 2005, p. 22-23).

É importante destacar o sentido das palavras master e class, ou seja, aula do mestre, é a aula durante a qual todos os discípulos estão reunidos para desfrutar e tentar alcançar um pouco do conhecimento do professor. Não é por acaso que Daniel denomina o professor de master class com a palavra gatekeeper (gate - portão, keeper - guarda), palavra que muitas vezes, utilizada metaforicamente, tem o sentido de quem decide o que deve ou o que não deve ser transmitido ou utilizado.

Cristina Tourinho (2008, p. 1) também nos apresenta sua opinião sobre o tema:

Tenho visto muitos professores utilizarem-se de master class, ensaios, orquestras de violões e chamarem este trabalho de ensino coletivo. Embora todas estas atividades façam parte das aulas de ensino coletivo, este se caracteriza por trabalhar $a$ priori um repertório individual, no mesmo espaço e para vários estudantes simultaneamente. Não se trata de "atividades em grupo", mas de aulas compartilhadas, onde a interação e auto-observação são imprescindiveis.

Superando possiveis polêmicas e datas uma sintese do assunto pode ser feita. Podemos perceber que o sistema de ensino coletivo de música surgiu a partir do início do século XIX e sua criação deveu-se à necessidade de mais bem aproveitar os recursos disponiveis e diminuir custos, atendendo a mais alunos e, no caso dos primeiros exemplos do sistema, expandindo o mercado consumidor de instrumentos e publicações musicais. Guardadas as devidas proporções, tais motivos ainda são pertinentes e fundamentam a importância do ensino coletivo na atualidade: a praticidade e o melhor aproveitamento de esforços do professor, melhorando o rendimento do ensino e principalmente a relação custo-beneficio das aulas.

Sobre isso, Montandon (1992, p. 12-13), apoiada em Monsour (1963), também cita alguns fatores que contribuiram para o sucesso da aula de piano em grupo, dentre eles as questões econômicas, como o alto preço das aulas individuais, o interesse comercial das fábricas de instrumentos e editoras e as novas tendências educacionais centradas na criança e na valorização de atividades artísticas que propiciassem a elas experiências culturais.

$\mathrm{Na}$ mesma linha de raciocínio, o trabalho de mestrado de um dos autores deste artigo também indica um caminho argumentativo para esclarecer a consolidação da metodologia de ensino coletivo, pois nele é afirmado que, na passagem do século XIX para o XX, as mudanças ocorridas no pensamento

\footnotetext{
${ }^{13}$ Depois de encerrar sua carreira de concertista, Liszt optou pelo sistema de master class para atender seus
} alunos, levando o sistema aos extremos e atendendo a dezenas de alunos em suas aulas. 
pedagógico e na estrutura do ensino, tanto na América do Norte como na Europa, transformaram o modo de transmissão de conhecimento, alterando o enfoque pedagógico e fazendo com que os métodos que privilegiassem a simples repetição ou imitação perdessem espaço para aqueles que enfatizavam o desenvolvimento da capacidade de agir e pensar. Tal ambiente propiciou o surgimento de novas ideias e concepções que influenciaram também o ensino musical (Santos, 2001, p. 17).

\section{O ENSINO COLETIVO DE INSTRUMENTOS MUSICAIS NO BRASIL}

Ao contrário das dificuldades de detectar precisamente o histórico do ensino coletivo na Europa e EUA, o surgimento do ensino coletivo de instrumentos musicais no Brasil parece não suscitar dúvidas.

Vários autores, entre eles Galindo (2000), Santos (2001), Almeida (2004), Ying (2007) e Silva (2008), convergem para três focos de ensino entre as décadas de 1960 e 1970: o ensino coletivo de instrumentos de sopro, realizado empiricamente na cidade de Tatuí (SP), no início dos anos 1960, por José Coelho de Almeida; o ensino coletivo de cordas, implantado por Alberto Jaffé em Fortaleza, a partir de 1975; e o ensino coletivo de piano, a partir dos trabalhos de Robert Pace e de Maria Junqueira Gonçalves, iniciados por volta de 1976 e 1979, respectivamente, no Rio de Janeiro.

Segundo relato do próprio professor Almeida (2004, p. 17), as circunstâncias (necessidade de ensinar vários alunos, com poucos professores, quantidade limitada de instrumentos e de recursos financeiros) levaram-no a adotar o sistema para conseguir montar uma banda musical com os filhos de funcionários de uma tecelagem:

O Sr. João Chammas queria que eu fizesse a banda. Imagine se naquele domingo eu dissesse que precisava de professores para os diversos instrumentos para ensinar os meninos! Professores: de clarineta, saxofone, trompete, trompa, trombone, bombardino, tuba, percussão, o projeto estaria morto, porque inviabilizado economicamente.

Mesmo que naquele momento não tivesse profundo conhecimento pedagógico sobre o assunto, o professor optou pela solução do ensino coletivo e começou a ler e a estudar o material disponivel na época:

Procurei imediatamente toda a literatura disponivel sobre o assunto existente nas livrarias e bibliotecas de São Paulo. Pouca coisa encontrei. Entre os livros, encontrei o de Edgar Willems, Las bases psicológicas de la educación musical, que a editora Editorial Universitária de Buenos Aires acabara de publicar do original francês [...] Estudei vários livros de pedagogia musical, nacionais e estrangeiros. Livros de instrumentação de orquestra e de banda, de regência, de estética e acústica, de história da música e de história dos instrumentos musicais foram lidos com avidez. Os métodos de todos os instrumentos foram 
estudados profunda e detalhadamente. Aprendi, em poucos dias, todos os dedilhados dos instrumentos de madeira e de metal (Almeida, 2004, p. 18).

Na verdade, a inteligência e perspicácia do professor levaram-no a encontrar a melhor maneira, ou a maneira que propiciasse bons resultados. Não podemos esquecer que Tatuí, a cidade onde o professor implantou o projeto, já possuía o único conservatório do governo do estado de São Paulo e uma associação que mantinha uma pequena orquestra:

Já tínhamos em Tatuí o Conservatório Dramático e Musical "Dr. Carlos de Campos", instalado em 11 de agosto de 1954, e a Associação Cultural Pró-Música, criada em 1951, e que mantinha, a duras penas, uma pequena orquestra sinfônica (Almeida, 2004, p. 13).

Além disso, a região mantinha uma tradição vinda das bandas musicais formadas por imigrantes europeus e escravos alforriados, associados em um interessante exemplo de convivência cultural.

Desde o século XVII a riqueza dos minerais existentes no Morro do Ipanema, uma área de extração nas proximidades da cidade, atraía interesse de governantes e empreendedores e, posteriormente, a partir da implementação de projetos siderúrgicos no local, houve a imigração de operários europeus que trouxeram seus instrumentos, fazendo com que a vida musical da região passasse a ser movimentada, culminando com a criação de várias corporações musicais.

As minas de ferro do Ipanema são um referencial cultural para nossa região, pois foram os suecos e alemães responsáveis por trazerem da Europa instrumentos, conhecimento musical e o gosto pela música que foram passados aos seus descendentes e principalmente aos escravos da região, determinando mudanças no panorama histórico e sociocultural, onde a música passa a ser um fator de suma importância, pois a grande característica da difusão cultural é ela ser o primeiro processo de integração e civilizador de um povo. Pode-se em parte, atribuir a ela um fato histórico particular: antes da abolição da escravatura, os escravos tatuianos estavam todos alforriados, isto é libertos. A música percorreu a antiga estrada do Vai e Vem (que hoje não existe mais), que fazia a ligação entre Tatuí - Fábrica do Ipanema - Sorocaba, que teve papel importantíssimo para a cultura de Tatuí, pois, por ordem régia, os moradores da Fábrica do Ipanema eram proibidos de cortarem madeira e utilizarem as terras na área em que se achava instalada a "Real Fábrica de Ferro de São João de Ipanema" [...].

Foi através desse fato, que provocou a vinda dos moradores ao sítio de "Tatuhu", que a música se instalou definitivamente na sociedade local (Delarole, 2010, p. 31-33). 
Muitos anos depois essa tradição facilitou e motivou tal iniciativa, pois havia uma demanda de pessoas querendo estudar música; não é por acaso que hoje a cidade tem o mais importante conservatório de música do Brasil, com um grande número de profissionais formados e atuando nas maiores e melhores orquestras e bandas brasileiras e internacionais.

Curiosamente a implantação do ensino coletivo de instrumentos de cordas em nosso país também seguiu um processo predominantemente empírico, pois o professor Alberto Jaffé, necessitando criar uma maneira de incentivar seus filhos e alunos a estudarem mais e se desenvolverem mais rapidamente, lançou mão do sistema de ensino coletivo. É assim que nos relata o professor Marco Antonio Silva (2008, p. 12-13):

Esse método foi aplicado [a] partir de um simples fato do cotidiano. Ao observar seus filhos com pouco rendimento individual em suas lições de música, quando praticavam sozinhos, o professor Jaffé percebeu que seu desempenho melhorava quando eles tocavam com seus colegas. O professor Jaffé percebeu que os alunos, ao passarem do estudo de música individual para o coletivo, obtinham um resultado mais efetivo. O professor, então, passou a utilizar um procedimento de ensino coletivo juntando seus filhos e alunos. Ao perceber os resultados didáticos desta prática, sua visão sobre o ensino coletivo alcançou proporções mais amplas, levando-o a implementar uma metodologia com esse objetivo.

Com o sucesso da tentativa, Jaffé foi convidado pelo presidente da Confederação Nacional da Indústria (CNI) a implantar, a partir de 1975, o sistema no Serviço Social da Indústria (Sesi) de Fortaleza, com a finalidade de atender aos filhos dos operários daquela região.

Esse trabalho motivou o governo brasileiro a criar, por meio da Fundação Nacional de Artes (Funarte), um novo projeto, o Projeto Espiral, e por esse motivo a família Jaffé em 1978 transferiu-se para Brasília, com a finalidade de coordenar o primeiro núcleo, conforme relata Ying (2007, p. 22):

O projeto de Alberto Jaffé chamou a atenção das autoridades federais. O Ministério da Educação e Cultura (MEC), através da Fundação Nacional das Artes (FUNARTE), propôs a implantação de vários centros de ensino coletivo de cordas por todo o Brasil, iniciando por Brasília em 1978, para onde a família Jaffé se mudou. Esse projeto foi chamado de Projeto Espiral, e originalmente o professor Jaffé criaria e implantaria os centros, sendo diretor pedagógico de cada unidade, onde monitores especialmente treinados por ele iriam utilizar e aplicar sua metodologia.

Entretanto as condições politicas não permitiram a continuidade do trabalho, e Jaffé desligou-se do projeto e mudou-se para São Paulo com o intuito de implantar um novo trabalho, dessa vez, ligado ao Serviço Social do Comércio (Sesc): 
A experiência de Fortaleza resistiu a várias crises, inclusive quando da substituição do empresário Thomas Pompeu de Sousa Brasil Netto na presidência da Confederação Nacional de Indústria. A filosofia de seu substituto era contrária à manutenção de programas na área cultural, no modelo do Espiral. Em consequência disso, Jaffé foi afastado do Núcleo de Fortaleza e de Brasília. O afastamento do professor Jaffé interrompeu o projeto nos moldes implantados inicialmente. Embora com outras diretrizes, o núcleo na cidade de Fortaleza permaneceu ativo sob a orientação de outro professor (Silva, 2008, p. 14).

Na década de 1980 o professor transfere-se para os EUA, onde inicialmente é codiretor do Departamento de Música da Academia de Artes, na cidade de Champaign (Illinois) e, depois, professor na Universidade de Illinois e na Pensacola Christian College.

\begin{abstract}
Alberto Jaffé implantou um método que tem como objetivo a formação em massa de músicos de instrumentos de cordas. $\mathrm{O}$ autor acreditava que o ensino coletivo seria o meio pelo qual se poderia alcançar esse objetivo [...].

Esse método, inicialmente desenvolvido para o violino, foi posteriormente aplicado à viola, violoncelo e contrabaixo. Essa expansão foi possivel através da utilização de elementos-chave da técnica comum aos quatro instrumentos da família das cordas. Isso facilitou a abordagem simultânea de vários alunos e a evolução conjunta do aprendizado.

No cenário musical brasileiro da época onde prevalecia o formato de ensino herdado dos conservatórios europeus, Jaffé procurou introduzir uma nova proposta. Aplicar um método de ensino coletivo que formasse instrumentistas em número satisfatório para as orquestras (Silva, 2008, p. 19-20).
\end{abstract}

Ao contrário do ensino coletivo de sopros, implantado em Tatuí, e o de cordas, implantado inicialmente em Fortaleza, os primeiros exemplos de ensino coletivo de piano não foram experiências empíricas. A implementação do sistema para o instrumento surgiu dentro das escolas ou universidades e logo nos primeiros momentos procurou-se desenvolver pesquisas na área.

A partir das informações da dissertação de Montandon (1992), da tese de Santos (2016) e dos trabalhos de Ana Paula Reinoso (2012a, 2012b) é possivel realizar um mapeamento da implantação do ensino coletivo de piano em nosso país. Ela aconteceu a partir do ano de 1975, quando a professora Abigail Rodrigues da Silva retorna dos EUA onde se especializou em didática do ensino de piano em grupo pela Universidade Colúmbia, ${ }^{14}$ tornando-se

\footnotetext{
${ }^{14}$ Essa informação consta da tese de Santos (2016), que utiliza como referência as páginas eletrônicas das professoras Abigail Silva e Maria Junqueira Gonçalves; no entanto essas duas páginas foram retiradas do ar: a professora Abigail Silva transferiu sua página na internet para o Facebook e a professora Maria Junqueira Gonçalves faleceu em 2015. Sem dúvida o ensino coletivo perde uma referência importante com o encerramento dessas páginas.
} 
diretora do método Robert Pace no Brasil e iniciando os cursos de capacitação do método em Belo Horizonte (1975) e em São Paulo (1976).

Em 1977 a professora Abigail organiza, na cidade de Santo Amaro (SP) o primeiro congresso do método Robert Pace; nesse evento a professora Maria Junqueira Gonçalves trava contato com a metodologia de Pace, ${ }^{15}$ conforme relata: "Antes de, oficialmente, iniciar meus trabalhos de pesquisa, em janeiro de 1977 - no período de férias - fui a São Paulo para participar do $1^{\circ}$ Congresso Nacional do Método de Ensino de Piano em Grupo Robert Pace" (Santos, 2016, p. 31).

A partir de então, enquanto a professora Abigail continua seu trabalho de divulgação do método, a professora Maria Junqueira inicia um trabalho intenso de pesquisas bibliográficas e estudos práticos na área, e um ano depois recebe uma bolsa da Fulbright Comission para aprofundar suas investigações sobre o assunto:

O que na verdade ocorreu foi que, quando desenvolvi meu primeiro projeto de pesquisa - Ensino de Piano em Grupo - nova abordagem de ensino de instrumento, na UFRJ, solicitei e obtive uma bolsa de estudos da COMISSÃO PARA INTERCÂMBIO ENTRE OS ESTADOS UNIDOS DA AMÉRICA E O BRASIL [...]. Foi então que tive a oportunidade de pesquisar metodologia e aplicação do ensino de piano em grupo (Santos, 2016, p. 32).

Após seu retorno ao Brasil a professora implanta um curso de pós-graduação na UFRJ (especialização em ensino de piano em grupo); as aulas tiveram início no ano de 1979. A partir de então, o sistema de ensino coletivo de piano foi se propagando, seja por meio de cursos de qualificação ministrados pelas professoras citadas, seja pela atuação de suas alunas ou ainda pelo trabalho de pesquisadores independentes.

Um ponto que merece destaque é a diferença entre os caminhos do ensino em grupo de piano, que no Brasil nasceu dentro da academia (ou nas escolas e conservatórios), e do ensino coletivo de sopros e cordas, que foi desenvolvido para atender situações de ensino não formal, onde se necessitava instruir alunos com minimos recursos.

Provavelmente esse fato motivou diferenças, que culminaram com a estruturação mais rápida do ensino de piano em grupo dentro da universidade. Atualmente essa diferença não existe e o ensino coletivo de instrumentos encontra-se estruturado dentro e fora da academia, contando com uma quantidade considerável de iniciativas desenvolvidas, trabalhos realizados, artigos, dissertações e teses escritas.

\footnotetext{
15 A professora já conhecia a metodologia de piano em grupo, pois seu projeto de pesquisa na área havia sido aceito na UFRJ no final de 1976. Mas é inegável que o congresso em questão foi marcante em sua decisão de aprofundar estudos na área.
} 


\section{CONCLUSÃO}

O presente artigo teve a intenção de colaborar com a construção de um histórico sobre o ensino coletivo de instrumentos musicais. Todas as observações elencadas e discutidas, referentes ao conceito histórico das primeiras utilizações do sistema, estão embasadas em documentos e trabalhos científicos. Por esse motivo algumas conjecturas relacionadas ao tema foram descartadas, pois ainda carecem de comprovação científica; esse fato não desmerece tais suposições ou os autores (muitos de referência) que as fizeram, apenas trata-se de uma decisão sobre qual informação será ou não utilizada no texto. Tal procedimento, eventualmente, nos obriga a abrir mão de dados que a princípio podem nos parecer importantes, mas que (ainda) não podem ser confirmados por meio dos procedimentos científicos.

De todo modo, o simples fato de levantar discussão sobre o processo histórico de implantação do ensino coletivo de instrumentos musicais e sobre o início da utilização do sistema em nosso país parece-nos apontar um sentido e pertinência para o presente trabalho.

Finalmente, é importante registrar que ainda nos falta, nessa área, a aplicação prática dos resultados das pesquisas realizadas, ou seja, que os valores financeiros e esforços investidos na pesquisa científica sobre o assunto sejam aproveitados quando da adequação ou implantação de novos projetos. Apenas dessa forma faremos uso adequado e racional dos recursos investidos tanto nas pesquisas como na criação e manutenção de projetos de ensino de música.

\section{REFERENCIAS}

ALMEIDA, José Coelho de. O ensino coletivo de instrumentos musicais: aspectos históricos, políticos, didáticos, econômicos e socioculturais. Um relato. In: ENCONTRO NACIONAL DE ENSINO COLETIVO DE INSTRUMENTOS MUSICAIS (ENECIM), 1., 2004, Goiânia. Anais [...] Goiânia: UFG, 2004. p. 11-29.

BALLES, William L. The instrumental preceptor. New York: Cornish, Lamport \& Co.; St. Louis: McCarthey \& Lamport, 1851.

CRUVINEL, Flávia Maria. Educação musical e transformação social: uma experiência com ensino coletivo de instrumentos de cordas. Goiânia: Instituto Centro-Brasileiro de Cultura, 2005.

DANIEL, Ryan James. Challenging the orthodoxy: an alternative strategy for the tertiary teaching of piano. 2005. Tese (Doutorado em Filosofia) - College of Music, Visual Arts and Theatre, James Cook University, Townsville, 2005.

DELAROLE, Pedro Juliano. O Conservatório Dramático e Musical "Dr. Carlos de Campos" de Tatuí como difusor cultural. 2010. Dissertação (Mestrado em Musicologia) - Escola de Comunicação e Artes, Universidade de São Paulo, São Paulo, 2010. 
DEVERICH, Robin Kay. Violin pedagogy: how did they learn? Classes for the masses in England. In: DEVERICH, Robin Kay. Violin Online. [S. l.], 2013. Disponivel em: http://www.violinonline.com/classesforthemassesinengland. htm. Acesso em: 1 jul. 2019.

DILLON, Brenda. The impact of group piano and technology. Roland Keyboard Educator, v. 3, n. 3, p. 1, 9, 1999.

EHRLICH, Cyril. The piano: a history, revised edition. Oxford: Clarendon Press, 1990.

FERREIRA, Aurelio B. Novo Aurélio. Rio de Janeiro: Nova Fronteira, 1999.

FISHER, Christopher. Teaching piano in groups. New York: Oxford, 2010.

GALINDO, João Maurício. Instrumentos de arco e ensino coletivo: a construção de um método. 2000. Dissertação (Mestrado em Musicologia) Escola de Comunicação e Artes, Universidade de São Paulo, São Paulo, 2000.

JØRGENSEN, Harald. Student learning in higher instrumental education: who is responsible?. British Journal of Music Education, v. 17, n. 1, p. 67-77, 2000 .

KEENE, James A. A history of music education in the United States. 2. ed. Centennial: Glenbridge, 2009.

LOESSER, Arthur. Men, women and pianos: a social history. New York: Simon \& Schuster, 1954.

MARK, Michel L.; GARY, Charles L. A history of american music education. 3rd ed. Maryland: Rowman \& Littlefield Education, 2007.

MONSOUR, Sally A. The establishment and early development of beginning piano classes in the public schools, 1915-1930. 1959. Tese (Doutorado em Educação) - University of Michigan, Ann Arbor, 1959.

Piano classes are not new. Clavier, v. 2, n. 5, p. 32-35, Oct. 1963.

MONTANDON, Maria Isabel. Aula de piano e ensino de música: análise da proposta de reavaliação da aula de piano e sua relação com as concepções pedagógicas de Pace, Verhaalen e Gonçalves. 1992. Dissertação (Mestrado em Educação Musical) - Instituto de Artes, Universidade Federal do Rio Grande do Sul, Porto Alegre, 1992.

Ensino coletivo, ensino em grupo: mapeando as questões da área. In: ENCONTRO NACIONAL DE ENSINO COLETIVO DE INSTRUMENTOS MUSICAIS (ENECIM), 1., 2004, Goiânia. Anais [...] Goiânia: Universidade Federal de Goiás, 2004. p. 44-48. 
OLIVEIRA, Enaldo de. O ensino coletivo dos instrumentos de cordas: reflexão e prática. 1998. Dissertação (Mestrado em Musicologia) - Escola de Comunicação e Artes, Universidade de São Paulo, São Paulo, 1998.

REINOSO, Ana Paula T. A inserção do ensino de piano em grupo no Brasil: episódios marcantes. In: SIMPÓSIO BRASILEIRO DE PÓS-GRADUANDOS EM MÚSICA (SIMPOM), 2., 2012, Rio de Janeiro. Anais [...] Rio de Janeiro: Universidade Federal do Estado do Rio de Janeiro, 2012a. p. 1110-1117.

O ensino de piano em grupo em universidades públicas brasileiras. 2012. Dissertação (Mestrado em Música) - Centro de Letras e Artes, Universidade Federal do Rio de Janeiro, Rio de Janeiro, 2012b.

RODRIGUES, Társilla Castro. Ensino coletivo de cordas friccionadas: uma análise da proposta metodológica de ensino coletivo de violino e viola do Programa Cordas da Amazônia. 2012. Dissertação (Mestrado em Artes) Instituto de Ciências da Arte, Universidade Federal do Pará, Belém, 2012.

SANTOS, Wilson R. Orquestras-escola: estudo e reflexão. 2001. Dissertação (Mestrado em Artes - Música) - Instituto de Artes, Universidade Estadual Paulista, São Paulo, 2001.

Educação musical coletiva com instrumentos de arco: uma proposta de sistema em niveis didáticos. 2016. Tese (Doutorado em Música Educação Musical) - Escola de Música, Universidade Federal da Bahia, Salvador, 2016.

SILVA, Marco Antonio. Reflexões sobre o método Jaffé para instrumentos de cordas: a experiência realizada em Fortaleza. 2008. Dissertação (Mestrado em Música) - Centro de Ciências Humanas, Letras e Artes, Universidade Federal da Paraíba, João Pessoa, 2008.

SOLLINGER, Charles E. The music men and the professors: a history of string class methods in the United States, 1800-1911. 1970. Tese (Doutorado em Educação) - School of Education, University of Michigan, Ann Arbor, 1970.

String class publications in the United States, 1851-1951. Detroit: Information Coordinators, 1974.

THOMPSON, Kevin. An analysis of group instrumental teaching: principles, procedures and curriculum implications. 1983. Tese (Doutorado em Educação) - Institute of Education, University of London, London, 1983.

TOURINHO, Ana Cristina. O ensino coletivo na educação básica e em espaços alternativos: utopia ou possibilidade?. In: ENCONTRO REGIONAL CENTRO-OESTE DA ABEM, 8.; ENCONTRO NACIONAL DE ENSINO COLETIVO DE INSTRUMENTO MUSICAL (ENECIM), 3., 2008, Brasília. Anais [...] Brasília: Universidade de Brasília, 2008. p. 1-9. 
YING, Liu Man. O ensino coletivo direcionado no violino. 2007. Dissertação (Mestrado em Musicologia) - Escola de Comunicação e Artes, Universidade de São Paulo, São Paulo, 2007.

ZHUKOV, Katie. Problems of research into instrumental music teaching. In: AUSTRALIAN SOCIETY FOR MUSIC EDUCATION NATIONAL CONFERENCE, 12., 1999, Sydney. Proceedings [...] Baulkham Hills: Australian Society for Music Education, 1999. p. 247-251. 
Wilson Rogério dos Santos é professor adjunto da Universidade Federal do Tocantins (UFT), lecionando Música no curso de Licenciatura em Educação do Campo no Campus de Arraias. É membro e pesquisador do Gabinete de Investigação em Educação Musical da UFT, do Grupo de Pesquisa em Ensino de Instrumentos Musicais da Universidade Federal da Bahia (UFBA) e do Grupo de Estudos do Som e Processos Criativos da Universidade Estadual de Campinas (Unicamp). Sua área de interesse e pesquisa é o ensino coletivo de instrumentos; as narrativas transmidiáticas; música e desenvolvimento humano e etnomusicologia. É doutor em Música - Educação Musical pela UFBA, mestre em Artes - Música pela Universidade Estadual Paulista (Unesp) e bacharel pela Unicamp nas áreas de Composição e Regência. Em 2019 realizou estágio pós-doutoral na Unicamp. Publicou artigos na Revista de Estudios e Investigación en Psicología y Educación; Vórtex; Ouvirouver; Ciências da Sociedade, entre outras. É organizador dos livros: Educação cultura e etnodesenvolvimento e Educação musical na educação do campo, ambos publicados pela EdUFT. https://orcid.org/0000-0001-9912-7164

Ana Roseli Paes dos Santos é professora da Universidade Federal do Tocantins (UFT), no curso de Licenciatura em Educação do Campo com habilitação em Artes Visuais e Música. É líder do Gabinete de Investigação em Educação Musical da UFT, faz parte do Grupo de Pesquisa em Ensino de Instrumentos Musicais da Universidade Federal da Bahia (UFBA) e do Instituto de Etnomusicologia da Universidade de Aveiro (INET-MD), Portugal. Sua área de interesse é educação musical, ensino coletivo de instrumentos, formação de professores de música, etnopedagogia musical e etnomusicologia. É doutora em Estudos da Criança - Educação Musical pela Universidade do Minho, mestra em Educação pela Universidade Estadual de Campinas (Unicamp) e bacharela pela Unicamp. Em 2020 realiza estágio pós-doutoral no Departamento de Comunicação e Arte da Universidade de Aveiro. Publicou artigos na Revista de Estudios e Investigación en Psicología y Educación; Vórtex; Criar Educação, entre outras. É organizadora dos livros: Educação cultura e etnodesenvolvimento e Educação musical na educação do campo, ambos publicados pela EdUFT. https://orcid.org/0000-0003-4684-5351 